\title{
Effect of Karanja extract treatment on weight per unit area of fabric
}

Received: 19.12.2017; Revised: 29.03.2018; Accepted: 16.04 .2018

See end of the paper for authors' affiliations

\section{Puspa}

Department of Textile and Apparel Designing, College of Home Science, C.C.S. Haryana Agricultural University, Hisar (Haryana) India

Email : ptomer07@gmail.com
ABSTRACT : The objectives of this study were to determine physical property of control and treated samples were tested to analyze the effect of Karanja extracts on the samples. The fabric samples were conditioned. Samples were cut from scoured cotton fabric with 54 warp yarns (ends) and weft yarns (picks) per inch were (ASTM 123 test method). The tests were performed for different types of samples viz., control (scoured), samples treated with leaves and seed extracts in viscous and dry state; and samples treated with an antiseptic containing chloroxylenol. The samples were subjected to tests for weight per unit area $\left(\mathrm{g} / \mathrm{m}^{2}\right)$ physical property test. It was concluded that as the concentration of extract increased, significant increase at $1 \%$ level of significance was observed in all treated samples except SDLP. This may be due to the fact that increase in concentration of Karanja extract, lead to absorption of more amount of extract by the sample.

KEY WORDS: Viscous, Chloroxylenol, Antiseptic, Methanol, Soxhlet method

- HOW TO CITE THIS PAPER : Puspa, Singh, V. and Punia, P. (2018). Effect of Karanja extract treatment on weight per unit area of fabric. Asian J. Home Sci., 13 (1) : 146-150, DOI: 10.15740/HAS/ AJHS/13.1/146-150. Copyright@ 2018: Hind Agri-Horticultural Society. 